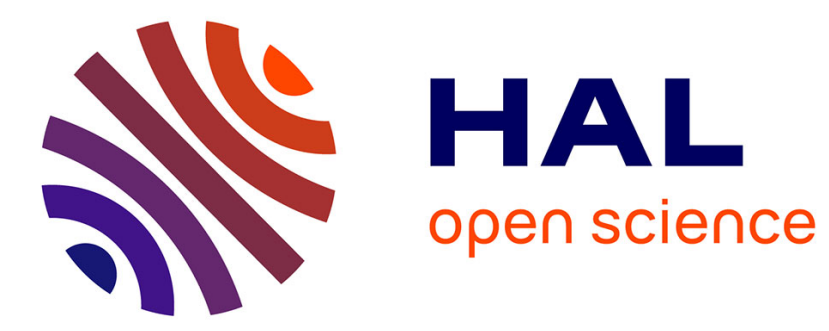

\title{
Reframing problems of incommensurability in environmental conflicts through pragmatic sociology. From value pluralism to the plurality of modes of engagement with the environment
}

Laura Centemeri

\section{To cite this version:}

Laura Centemeri. Reframing problems of incommensurability in environmental conflicts through pragmatic sociology. From value pluralism to the plurality of modes of engagement with the environment. Environmental Values, 2014, pp.xx-xx. 10.3197/096327114X13947900181158 . hal-01015992

\author{
HAL Id: hal-01015992 \\ https://hal.science/hal-01015992
}

Submitted on 29 Jul 2014

HAL is a multi-disciplinary open access archive for the deposit and dissemination of scientific research documents, whether they are published or not. The documents may come from teaching and research institutions in France or abroad, or from public or private research centers.
L'archive ouverte pluridisciplinaire $\mathbf{H A L}$, est destinée au dépôt et à la diffusion de documents scientifiques de niveau recherche, publiés ou non, émanant des établissements d'enseignement et de recherche français ou étrangers, des laboratoires publics ou privés. 


\title{
Reframing problems of incommensurability in environmental conflicts through pragmatic sociology. From value pluralism to the plurality of modes of engagement with the environment.
} Laura Centemeri (CNRS/LAMES/AMU)

Accepted for publication in Environmental Values.

\begin{abstract}
This paper presents the contribution of the pragmatic sociology of critical capacities to the understanding of environmental conflicts. In the field of "environmental valuation", nowadays colonised by economics, the approach of plural modes (or "regimes") of engagement provides a sociological understanding of the unequal power of conflicting "languages of valuation". This frame entails a shift from "values" to "modes of valuation" and links modes of valuation to modes of practical engagement and coordination with the surrounding environment. Different social sources of incommensurability are thus detected and reframed as critical tension within and among modes of human coordination with the environment.
\end{abstract}

\section{Keywords}

Incommensurability, environmental valuation, pragmatic sociology, value conflict, decision 


\section{Introduction}

In this paper I discuss the contribution that the "sociology of critical capacities" - also known as French pragmatic sociology - initiated by Luc Boltanski and Laurent Thévenot (Boltanski and Thévenot, 1999; Boltanski and Thévenot, 2006) makes to the study of environmental conflicts. Emerging in France in the 1980s, as a challenge to Pierre Bourdieu's "critical sociology", this approach has progressively elicited an international echo and is today a key reference in the European debate. ${ }^{1}$ Environmental conflicts have proved to be among the most fruitful fields of application of French pragmatic sociology in recent years ${ }^{2}$. This should not be surprising given the fundamental contribution of Bruno Latour's works to the development of this approach (Guggenheim and Potthast, 2012). In fact, one of the most innovative traits of the "pragmatic turn" in French sociology (Dosse, 1999) is to consider "nonhumans" as “agents", assuring and stabilising coordination between human beings.

The concepts of "hybrid forum", "translation", "framing" and "overflowing" elaborated by Michel Callon to address environmental disputes have greatly contributed to a more accurate sociological analysis of what economists (and increasingly activists, politicians and citizens) call "environmental externalities" (Callon, 1998; Callon et al., 2009). Nevertheless, the actornetwork approach fails to provide an account of what translations - and mediations - entail in terms of the need to conciliate competing and incommensurable "languages of valuation" of the environment. The unequal power of these languages has been put forward as a reason that accounts for forms of oppression in contemporary environmental conflicts (Martinez-Alier,

\footnotetext{
${ }^{1}$ For a general presentation and discussion of French pragmatic sociology see Bénatouil (1999), Dodier (1993), Silber (2003), Wagner (1999) and the special issue of the European Journal of Social Theory edited by Blokker (2011). For a review of North American and European research on sociology of valuation and evaluation, to which French pragmatic sociology has given an important contribution, see Lamont (2012).

${ }^{2}$ See in particular the research conducted by Claudette Lafaye and Laurent Thévenot on environmental conflicts in France and the U.S. (Lafaye and Thévenot, 1993; Lafaye, Moody and Thévenot, 2000; Moody and Thévenot, 2000).
} 
2002; 2008). Moreover, value incommensurability is frequently mobilised to provide an account of why environmental conflicts so often turn into "intractable controversies" (Schön and Rein, 1994; Pellizzoni, 2003).

I argue that in the field of "environmental valuation", nowadays colonised by economics, pragmatic sociology could make a significant contribution by clarifying some of the underlying sociological issues accounting for these problems of incommensurability. The shift that pragmatic sociology promotes from values to modes of valuation and the link it establishes between modes of valuation and modes of action - these latter intended as modes of practical engagement and coordination with the environment - allow different social sources of incommensurability to be distinguished.

My argument is divided into four steps. First, I introduce the debate on incommensurability in environmental valuation, focusing on how it has been developed in the field of ecological economics and showing some sociological dimensions of the problem that have not been adequately addressed in this literature. Second, I introduce the pragmatic sociology approach to valuation. I argue that the most original contribution of this approach rests on showing a link between the modern construction of a precise "grammar" of the legitimacy of public valuation (the public justifiable valuation) and an idea of universal justice to which commensuration is fundamental. However, the public grammar of the valuable is far from being the only relevant language of valuation to which people have recourse. Following Thévenot $(2006,2007)$, two other grammars of the valuable can be identified: one based on functional utility, the other on familiarity and affection. Third, on this basis, I detail a first type of problem of incommensurability with which we are confronted in environmental conflicts, which I suggest should be defined as "order incommensurability". In this case, to commensurate is difficult, since multiple competing logics of general commensuration (or "orders of worth") can be mobilised by agents to define the value of the environment. 
Commensuration, however, is considered as the convenient mode of engagement with the environment: the problem is thus to find agreement on the appropriate logic of commensuration. This agreement is usually found through "public compromises" between incommensurable principle of valuation. The fourth step is designed to show the relevance in environmental conflicts of a different kind of problem of incommensurability: radical (or "constitutive") incommensurability. When radical incommensurability is at stake, we are confronted with languages and practices of valuation that are based on modes of engagement with the environment which do not rely on commensuration but on intimate and personal attachments to the environment built through familiarization. I will define this specific kind of engagement with the environment in terms of "dwelling". When dwelling, the humanenvironment relation is both that of a biological space to which human vital functions are connected and that of a "milieu" - a material and social place of proximity - in which the person and some of her capacities are "distributed" (Breviglieri, 2012). In conclusion, I discuss the political and ecological relevance of these modes of valuation based on familiarity and the challenges raised by the need to include them in the process of public decisionmaking.

\section{Problems of incommensurability in environmental valuation}

Incommensurability is a key concept of the critique addressed by ecological economics to the neoclassical economic understanding of problems of environmental valuation. ${ }^{3}$ In standard environmental economics, "environmental valuation" is a matter of putting a (market) price on the environment. The virtue of pricing environmental goods and functions is to allow commensuration between alternative options or courses of action. According to the utilitarian

\footnotetext{
${ }^{3}$ See Spash (1999), Martinez-Alier (2002) and Gowdy and Erickson (2005). On the limits of the market approach to environmental issues see especially O’Neill (2007).
} 
approach, which provides the theoretical basis of this mainstream economic approach, commensuration is a prerequisite for rational decisions.

In contrast, many of the economists joining ecological economics reframe environmental valuation as an "open social process", in which problems of value incommensurability are unavoidable. Value incommensurability - i.e., the existence of plural ways to value the environment irreducible to a single common standard of valuation - is presented as "a foundation stone for ecological economics” (Martinez-Alier, O’Neill and Munda, 1998).

In reframing environmental valuation as a social process, ecological economists rely upon the philosophical critique of the generalised commensurability implied by utilitarianism. According to this critique, incommensurability is unavoidable, since the goods a human being pursues in life so as to flourish are radically multiple. ${ }^{4}$ More specifically, vis-à-vis the generalised possibility of trade-offs assumed in the utilitarian tradition, the concept of “constitutive incommensurabilities" (Raz, 1986: 345-353) has been coined to point to certain social relations and evaluative commitments whose existence implies a refusal to trade them off: love and friendship are usually invoked as examples of such social relations, as well as certain modes of attachment to the environment (O’Neill et al., 2008: 79; Espeland, 1994).

Ecological economists rely on this critique of utilitarianism to challenge the idea of public decisions as "algorithmic solutions". As an alternative, deliberative models for decisionmaking are discussed as a possible way to take into account diverse modes of valuation in environmental problems. $^{5}$ The decision is analysed as the result of deliberation on

\footnotetext{
${ }^{4}$ The philosophical debate on value incommensurability was particularly lively at the end of the 1990s. See the book edited by Chang (1997) and the special issue of the University of Pennsylvania Law Review edited by Adler (1998). See also Sunstein (1994) and Nussbaum (2001). As noted by D'Agostino (2003), the philosophical debate has largely ignored the important sociological discussions on commensuration as a social phenomenon. See, in particular, Espeland and Stevens (1998) and Desrosières (1990; 1992; 1998).

${ }^{5}$ See the contributions collected in the book edited by Foster (1997). In addition, a "social multi-criteria" approach to decision has been promoted (Munda 2008), in which different forms of valuing a specific environment can be expressed and then combined, allowing for certain trade-offs to be excluded, especially - but not exclusively - for ecological reasons.
} 
environmental values, involving those who are affected by the decision process output. The direct implication of the so-called "stakeholders" in framing the decision process is proposed as a way to deal, not only with the pluralism of modes of valuation, but also with the "radical uncertainty" and ignorance that are distinctive traits, at the epistemic level, of environmental issues. That is why it has been suggested that ecological economics should be developed as a "post-normal science" and submitted to an "extended peer-review" process (Funtowicz and Ravetz 1994).

The idea that valuation is a "social process" to which incommensurability is key has become very popular in ecological economics literature. However, we can detect some sociological blind spots in the way in which environmental valuation is addressed as a social process in this debate. First of all, "values" are used as a sort of "black box" to point to alternative, noneconomic definitions of the valuable (i.e., not based on prices) without explaining why some of these definitions appear as more legitimate than others in the space of deliberation. Moreover, it is not clear in what terms "constitutive incommensurability" represents a specific challenge to deliberation.

In order to understand conflicts between different languages and practices of valuation of the environment, one must first define in what terms economic valuation is related to other noneconomic forms of valuation. Second, it is critical to explore the specific "grammar" of valuation on which public deliberation relies in our modern societies. However, in order to answer these questions, we need first of all to specify in what terms conflicting languages and practices of valuation differ. 


\section{Explaining languages and practices of valuation through regimes}

\section{of engagement}

In pragmatic sociology, the variety of modes of valuation is considered to be related to the same dynamic that explains the variety observable in human action. Valuation is in fact understood as the result of an evaluative judgment through which agents frame a given situation in order to carry out "the appropriate action" (Thévenot, 1990; Boltanski and Thévenot: 2006: 349). This judgement orients how they establish a relation (that is, engage and coordinate) with the surrounding environment and results in attributions of value to human and non-human beings. Action is thus understood as engagement and coordination with the environment: coordination is possible if actors share the same evaluative judgment on the situation, which implies sharing the same mode of engaging with human and nonhuman beings involved in the situation and to value them.

The judgement of "appropriateness" of an action to a given situation is considered crucial to the understanding of human action and implies an evaluative moment in its unfolding. This evaluation is based on the good that the agent can pursue through coordination with the social and material environment. Three types of good are referred to in pragmatic sociology as generally recognised in our societies as guiding human action: the "ease" of accommodation with a familiar and appropriated environment; the good of the fulfilment of a planned action; the "common good" beneficial to the polity as a whole (Thévenot, 1990; 2001; 2006; 2007). ${ }^{6}$

\footnotetext{
${ }^{6}$ By "common good", Boltanski and Thévenot (2006) refer to a political and historical construction: that of a principle of evaluation endowed with universality and intended to organise the polity as an ordered equilibrium oriented toward justice.
} 
On this basis, three main registers or modes of action - called "regimes of engagement" - are identified: the familiar regime, the regime in a plan (or normal regime of action) and the public justification regime (Boltanksi and Thévenot, 2006; Thévenot, 2007). ${ }^{7}$

The public justification regime of action has been the most extensively explored and discussed. It defines a mode of action and valuation, which is required by an agent in order to ensure the largest possible coordination - a "public" coordination - open potentially to every human being. In fact, according to Boltanski and Thévenot the "justifiable action" and its specific mode of valuation are the cornerstone of the modern construction of the "public sphere" as a distinct sphere of social life. The construction of the public sphere goes hand in hand with the definition of a specific mode of engagement and valuation of the surrounding human and material environment that is required for agents. In the way the public sphere has historically been built, the engagement required of agents is based on the qualification of human and non-human beings according to their worthiness in terms of a legitimate definition of the common good. Consequently, legitimate attributions of value are those establishing an order (of people and things in the situation) that is fair and just, since it respects their worth as evaluated from the standpoint of the common good.

The fairness and justice of these attributions of value are proved through appropriate "tests of reality". The concept of test of reality is key to the pragmatic understanding of evaluative practices' guiding action, and it is one of the most original contributions this approach provides for understanding legitimacy and justifiability in our societies. In the course of action, agents test the appropriateness of their evaluation, having recourse to specific objects and instruments expressly conceived or formatted to assess value or to more or less

\footnotetext{
7 "Regimes of engagement" are descriptive models of action. They are not the reconstruction of social reality and of its objective structures, nor are they predictive models of phenomena or behaviours. They look to clearly define the competences and resources to which each actor should have recourse, in order to produce a certain type of coordination with the social and material environment within a given context. Each model of action thus has its own corresponding "grammar" (Boltanski, 1990; Thévenot, 1990).
} 
formalized valuation practices involving the material surroundings. In the public regime of action, tests of reality are performed through instruments and equipment that objectively assess worth by establishing a "space of equivalence" based on the common good as the evaluative standpoint (Boltanski and Thévenot, 2006: 133-138). ${ }^{8}$ Consequently, commensuration is the operation at the heart of the reality tests designed to assess the legitimacy of a public attribution of worth.

The authors point out a specific feature of our modern society that accounts for its complexity: different definitions of the worth of people and things are equally held as publicly legitimate. In fact, plural specifications of the common good have historically emerged, implying that plural legitimate "orders of worth" are possible in our societies. In their research on practical modes of justification, Boltanski and Thévenot detect six different expressions of the common good in our society, defining these justifiable social and economic general orders by their corresponding modes of valuation: market competition, industrial efficiency, fame, civic solidarity, domestic trust, inspiration. As historically-defined conceptual constructions, orders of worth are not limited to these six, and new orders can always emerge, as shown by the work of Boltanski and Chiapello (2005) on the networkbased worth of contemporary capitalism and - especially relevant for environmental valuation - by the quite problematic emerging "green" order of worth discussed by Lafaye and Thévenot (1993). ${ }^{9}$ The result is that, in our societies, plural legitimate logics of commensuration can be used to define a general order. ${ }^{10}$

\footnotetext{
${ }^{8}$ For a synthesis of the discussion of objectivity from a pragmatic perspective, in terms of modes of "objectivation" implying a material intervention - or "investment" - to "format" the environment of action, see Centemeri (2012).

${ }^{9}$ Lafaye and Thévenot point out the difficulties of defining "forms of equivalence" that can allow for the existence of strong "tests of reality" of ecological worth. Moreover, the ecological order would entail enlarging the class of beings deserving of moral consideration beyond the "common humanity". This hypothesis radically challenges the model of polity on which orders of worth rely. On this point see Latour (1998) and Blok (2013).

${ }^{10}$ Commensurating is thus not necessarily monetising. Money is, historically, the most relevant tool ensuring commensuration in our societies, and the logics of using it so are plural, yet we can commensurate without
} 
Compared to the justifiable action, the "normal action" and the "familiar engagement" point to modes of coordination and valuation whose extension and public legitimacy are more limited. They are restricted, respectively, to those having a stake in the action and to those familiar with the environment. Consequently, moving from the normal action to the familiarity regime, the reality tests through which agents check on the appropriateness of their evaluation of the situation are progressively less dependent on a general standard assessing functions and needs and more embedded in knowledge produced and shared through a personalised practice.

Reading action through this plurality of modes of engagement, pragmatic sociology leads us to consider the human agent as plural in his/her ways to be an "agent-in-the-environment". The same person is capable of different kinds of agency - understood as diverse kinds of capacity to act - which are sustained by different modes of engaging with the environment: the personality with attachments in the familiar engagement, the individual with autonomy and interests in the normal action, the person acting for the common good in the justification regime. Accordingly, the surrounding environment is cognitively framed by agents as the familiar environment, functional objects, or conventional entities. Thus, the relevant information for testing the appropriateness of action depends on the mode of engagement with the environment: perceptual clues in the familiar regime, the ordinary language of functions and needs in the normal action, and codified language in the public action.

What I am interested in is that each regime points to a "practical grammar" of valuation. Valuation is based on legitimate conventions related to orders of worth in the justification regime: on utility in the regime of normal action; on personal attachments in the familiar

necessarily using money. (Zelizer 1997). Moreover, the choice to speak about "worth" instead of "value" is related to the fact that pragmatic sociology tries to overcome the so-called "Parsons' pact" (Stark, 2009: 7): that is, the clear-cut distinction between economic value (the legitimate domain of economics) and social values (the legitimate domain of sociology). For a discussion of incommensurability in terms of a social phenomenon anchored in the assumed divide between economic value and social values, as related to different spheres of life, see Trainor (2006). 
regime. The possibility of sharing these languages and practices of valuation with others, thus assuring coordination and agreement, is unequal. When an evaluation is based on the reference to a legitimate order of worth, the possibility of agreement or disagreement on the valuable is open to a "generalised third party", since the value can be objectively tested through appropriate instruments and tools collectively devised for this purpose (Boltanski and Thévenot, 2006). The conventions that qualify and frame the entities involved, according to general categories of worth, allow for an objective test of the value without requiring direct, in-depth knowledge of the situation. In contrast, agreement or disagreement requires a shared and direct experience of familiarisation when an evaluation is based on the familiar engagement. Nevertheless, far from being limited to the sphere of "the private", valuations resting on the ease ensured by personal arrangements can be shared with others, since they are understandable to others, they can be communicated and they can sustain critical claims.

However, critique based on valuations resting on familiarity cannot be easily expressed in the public space. The latter is historically and culturally built on the principle that legitimate forms of valuation require a "detached" perspective with regard to the relevant features accounting for the worth or the utility of something or someone: they require objectivity (Porter, 1995). Forms of valuing based on personal attachments can be understood by others and shared with them, but they are not acceptable as such as legitimate arguments in the public debate, where they have to be either translated (into interests) or compatibilized (through mediation) with legitimate definitions of worth (Doidy, 2003; Richard-Ferroudji, 2011). This is a structural reason accounting for the unequal power of languages of valuation observable in public deliberation. Similarly, the increasing importance attributed, for the legitimacy of public decision-making, to instruments such as cost-benefit analysis, creates a bias in favour of expressions of worth based on price and efficiency, denoting a strictly quantified expression of value. This has progressively reduced the place for justifiable modes 
of valuation, like the domestic one, which rely on appreciations of worth that are less bound to a quantified expression of value and that can be more "hospitable", I will argue, to valuations based on familiarity.

\section{The value of the environment in the public space:}

\section{incommensurability as "order incommensurability"}

If we conceive action as engagement and coordination with the environment, there is an inner tension, thus revealed, in the very word "environment" and its uses in our societies, with major consequences for understanding environmental valuation conflicts. In fact, what we call the "Environment" (meaning "Nature") is revealed as a specific way to qualify the environs or surroundings of some person, being or community, and to engage with it, in terms of public or normal action. In these two modes of action, a (human) subject is separated from and confronted with a (non-human) object, whereas in the familiar engagement, the frontier between subject and object is blurred.

In the public sphere, the environment matters as "Nature". The legitimate public modes of valuing nature are plural, and they unevenly rely on quantified and measurable expressions of value. Nature can be valued as "heritage", according to a domestic worth; or as expression of "wilderness", according to an inspired worth; or as a "place of renown", according to a worth based on fame. These "orders of worth" are examples of legitimate public modes of valuation that do not rely on a strictly quantified definition of value. Yet general, agreed-upon modes of objectifying value are at work here, based on codified knowledge and expert judgment that guarantee the possibility of ordering. When nature is valued as an "economic good" according to a market worth, or as a resource for production according to an industrial worth, quantified modes of valuation are introduced, in terms of prices or efficiency indicators. Nature can also be valued as a "public good" to which collective rights are associated: we can, then, speak of 
a civic mode of environment valuation. The increasing relevance of "biodiversity" as an expression of environmental value shows the progressive construction of a specific "green" order of worth based largely on scientific modes of quantification that seek to reveal the interdependencies linking - on ecological bases - the local to the global and the present to the future (Lafaye and Thévenot, 1993).

These plural modes of valuation all rest on an identical mode of engagement with the environment, which is the publicly justifiable mode of engagement: the environment is framed by agents through general and agreed upon categories of qualification. The environment is always a "qualified" environment: it is framed as the expression of a legitimate common good.

It is thus possible to identify a first kind of problem of incommensurability, with which we are confronted in environmental valuation conflicts. I propose to define it in terms of order incommensurability. By "problem of order incommensurability", I mean a critical situation in which there is difficulty in agreeing, in the public space, on the criteria of commensuration that are pertinent to test the legitimacy of a decision or action. When confronted with a problem of order incommensurability, disputes and controversies involve disagreement on how to commensurate, but they do not involve whether to commensurate. The conflicting valuations at stake all rest on a public justification engagement of the agents with the environment. The conflict does not involve the nature of the appropriate evaluative judgment: it involves the common good sought through coordination. The modes of valuation that sustain a coordination oriented towards market competition are not the same as those sustaining a coordination to achieve industrial efficiency, or civic solidarity. However, in all these cases, the kind of engagement with the environment required from agents is the same and it requires commensuration in order to successfully coordinate with others. 
The question that arises is how an agreement can be reached notwithstanding order incommensurability. A possible way out of this dilemma is to have one principle that dominates over the others. But from the evidence collected by Boltanski and Thévenot, the most frequent scenario is that of conflicting valuations reconciled in a "composite arrangement" or "compromise". In a compromise held in public - which is different from a private arrangement reached by mutual agreement of the actors involved or the negotiation of interests - the imperative of justification is not satisfied, but neither is it completely lost sight of: "In a compromise, the participants do not attempt to clarify the principle of their agreement; they are favourably disposed toward the notion of a common good without actively seeking one" (Boltanski and Thévenot, 2006: 277-278). In a compromise, different logics of commensuration are brought together to structure spaces of equivalence that are not completely coherent but are solid enough to sustain a justifiable evaluative judgment and the ensuing attributions of value. ${ }^{11}$

We can find such a compromise of valuations in apparently technical objects such as economic techniques of environmental valuation. These instruments usually incorporate plural ways of valuing the environment, beyond just market valuation, even if they ultimately produce a price for the environment. But this price is not a pure market price. The emphasis on price masks the importance of the "conventions of quantification" (Desrosières 1990), based on diverse principles of evaluation and coordination other than market principles. ${ }^{12}$

\footnotetext{
${ }^{11}$ In the domain of the environment, an example of what Boltanski and Thévenot call a "public arrangement for the common good" is the reference to "sustainable development" (Godard, 2003). Sustainable development refers to a largely underspecified "common good". That is why we can encounter so many different definitions of sustainability. Nevertheless, arrangements for sustainable development can be defended in public and they justify decisions and agreements or enable critique.

${ }^{12}$ See on this point the contribution to institutional economics by French Convention Theory (Dupuy et al., 1989; Favereau and Lazega, 2003; Thévenot et al., 2005). This economic approach has been developing in constant dialogue with pragmatic sociology. Economic value is shown as the result of "conventions" framing the reality according to definitions of the worth that are based on "compromises" between a market value and other logics of worth. Social values are, then, at work at the very heart of the construction of economic value in the conventions of qualification and quantification, which are necessary to define what is an economic good. This approach has been very fruitful for understanding issues of quality in economic life.
} 
An example of an analysis of economic valuation techniques, as objects incorporating compromises between diverse principles of justification, can be found in the research by Marion Fourcade on environmental damage valuation in France and the US (Fourcade, 2011). Interested in understanding the significant difference observed in court settlements following oil spills on the coast of Brittany in 1978 (the Amoco-Cadiz disaster) and Alaska in 1989 (the Exxon-Valdez disaster), the author shows how the techniques chosen to give a monetary valuation of the ecological damage in the two national contexts are heavily influenced by the specific forms of valuing "nature" that have emerged historically in the French and US cultures.

In the French case, following Fourcade's analysis, the way to discuss environmental valuation and compensation is dominated by a representation of nature as "domestic nature", that is, as an asset of the impacted region. The claim to ecological damage is left by the State to local populations and translated in terms of three different damages: "reputational loss" (loss of enjoyment of the area), the actual and future expenses necessary to restore coastal habitats and the loss of productive potential. Dimensions of industrial worth are taken into account here, together with market and fame valuations (summarized as reputational loss). The result is a composite qualification of the damage as damage to a "domestic" environment - not to "nature" - that is, to Brittany, as a specific cultural, economic and political region.

On the contrary, in the Exxon-Valdez case, the environmental damage was considered as damage to a "wild" and "untouched" nature: the shore of Alaska. In this case, compensation was meant to redress damage affecting the "wilderness". The valuation promoted was based on "inspiration", the beauty of wild nature, together with an ecological principle (biodiversity). The compensation process shows how the "inspired" and "ecological" valuations were "compatibilised" with a market valuation. 
The technique chosen to monetise the damage caused by the oil spill was "contingent valuation", a controversial technique which is grounded on "stated preferences" (O'Neill, 1997; Milanesi 2011). In fact, this technique is based on surveys on the "willingness to pay", in order to approach the representativeness that an anonymous market mechanism is supposed to ensure. In this specific case, the survey was designed to define the value that a pristine Prince William Sound, the bay affected by the spill, has for people who do not live in this specific region but might be interested in visiting it. The idea is to define the "lost use values" of the US, as a nation, following the accident. In fact, inhabitants of the affected region were explicitly excluded from the surveys: their way of judging the value of their environment was not considered representative, precisely because it was their environment. Contingent valuation is meant to reveal the value of "pristine nature" for the US public "in general", understood as a public of individuals with preferences and using these preferences as the basis for negotiation: it is the general (detached) attribution of value a "consumer" of "wilderness" would give to the affected area that matters as legitimate valuation.

Fourcade's research shows that valuation techniques establish a compromise between diverse attributions of value to the environment, temporarily "taming" order incommensurability. Moreover, behind these techniques of valuation, we can detect different ideas of the public and of public legitimacy. While in France, public legitimacy seems firmly grounded in the pursuit of the common good, in the American case, legitimacy is achieved through the expression of individual preferences and their negotiation, assuming a generalized possibility of trade-off. That is one of the reasons why, in the US case, the market order of worth plays such a central role in public life (Lamont and Thévenot, 2000).

Nevertheless, indirect indications of a different kind of problem of incommensurability can be detected in Fourcarde's article. As the author briefly mentions in her reconstruction of the US case, a separate claim by Native Alaskan tribes of injury to their special, collective way of life 
was rejected in court. She explains that $37.7 \%$ of the 900 million dollars compensation Exxon paid to the state and federal governments was used to buy out parcels of lands, mainly from Native American tribes, and set them aside for habitat protection. In a note, she adds that this policy has been highly controversial among Native Alaskans and she mentions a very tense relationship between Natives and ecologists. I argue that a specific problem of incommensurability, different from the problem of order incommensurability I have just discussed, is raised by the Native tribes' claim to the environment as a place of dwelling, not as wild nature.

\section{Valuing the environment as a place of dwelling: a "radical}

\section{incommensurability"}

In 1997 a group of Alaska Natives filed a class action against Exxon claiming non-economic damage to their "subsistence way of life". This latter is defined by the Ninth Circuit Court of Appeals judging their claim as "dependent upon the preservation of uncontaminated natural resources, marine life and wildlife", and reflecting "a personal, economic, psychological, social, cultural, communal and religious form of daily living". ${ }^{13}$

The Court, however, considered that the injury suffered by the Alaska Natives was different in magnitude, but not in kind, compared to the injury suffered by other Alaskans. Their injury was equivalent to the loss of individual enjoyment of environmental goods, such as the right to obtain and share wild food, enjoy uncontaminated nature, and cultivate traditional, cultural, spiritual and psychological benefits in pristine natural surroundings. Translated in this way, the loss by the Inuit communities was not deemed compensable as a different and specific injury. In fact, this translation of their loss in legal terms is based on an evaluation of the environmental damage that relies on the assumption that they are individuals who have a

\footnotetext{
${ }^{13}$ In re Exxon Valdez, 104 F.3d 1196, 1197 (9th Cir. 1997), emphasis mine.
} 
functional relationship with the environment. Normal engagement, in which what is valuable is what is useful for the individual, is assumed to be the "natural" reference to judge the relationships with the environment and the damage suffered following its disruption.

My argument is that the Alaskan Natives' claim, which can be seen as a claim for the legal acknowledgment of a "distinctive" relationship between indigenous peoples and their surroundings, ${ }^{14}$ points, in fact, to a specific mode of valuing the environment, which rests on an engagement on the basis of familiarity such as we all know and experience. Nevertheless, the extent to which the modes of valuation of this specific engagement with the environment are secured by the material and cultural devices structuring life in common in a political community is quite diverse across cultures. The emergence of a public dimension of collective life in Western societies came with the primacy accorded to engagements with the human and material surroundings based on the separation between subjects and objects, and between nature and culture. ${ }^{15}$

The Inuit case confronts us with a situation in which the political grammar structuring their life in common, their social and economic organisations, rests heavily on knowledge and valuation practices based on familiar engagement. In the liberal political grammar inspiring US and international institutions (of science, politics, law etc.), these practices and knowledge have been framed through the category of "indigenous culture", which assures their political legitimacy in terms of cultural specificity, to which rights can be attributed. Stressing the existence of an indigenous specificity risks, however, eclipsing the peculiar composition of plural languages of valuation that we can observe in these communities. Inuits are capable of engaging in functional terms with their environment and publicly justifying their critiques and claims; but the relative place of these forms of engagement in the organisation of their life in

\footnotetext{
${ }^{14}$ On this point, see Dannenmaier (2008).

${ }^{15}$ On the modern western "exceptionalism" of structuring of the relation to the environment in terms of "nature", see Latour (1993) and Descola (2005).
} 
common is different from that which we observe in our societies.

An example of the kind of issue that I wish to raise is offered by Picou (2000) through his research on the "recovering" of the Inuit communities affected by the Exxon Valdez disaster. Involved in 1994 in the design and implementation of a participatory mental health project in the fishing community of Cordova, funded by the Prince William Sound Regional Citizens' Advisory Council and meant to address the ongoing cultural and social disruption of Native communities after the spill, the author is confronted with the demand by the members of the Native Village of Eyak to hold a "talking circle" devoted to the Exxon Valdez disaster.

As explained by the author, talking circles are a specific institution in Alaska Native culture through which villagers collectively address matters of concern related to their life in common. Talking circles are open to all members of the village and they are not the place for debate or argument: they are meant for sharing one's feelings and thoughts with the rest of the village. That is why there are rules of confidentiality and uninterrupted discourse.

A two-day talking circle was thus organised in January 1996 and reframed as "a participatory intervention strategy". The author discusses how moments devoted to presenting scientific evidence of the environmental damage (such as ecological and economic damage) to the audience were followed by expressions of apology and sorrow (for all living creatures affected by the disaster) and "collective rituals" meant to restore and heal the environment. There was no lack of moments of denunciation, especially concerning Exxon's responsibilities. However, the Talking Circle was not meant to be a place to build a public critique. It was a way of collectively dealing with the environmental damage, as damage affecting valuable goods from a perspective of a familiar engagement. From this perspective, the environment is valuable since it is a dwelled-in environment. 
I use the expression dwelled-in environment to refer to a place that a person values because he/she moves and feels "at ease" in it, and because memories are deposited there. ${ }^{16}$ I consider a dwelled-in environment to be the environment we appropriate forging intimate bonds with human and non-human beings within it, thus creating a place in which interactions occur effortlessly. The person is "distributed" in his/her dwelled-in environment which becomes a constitutive part of the person so that, if affected, the consequences rebound directly on him/her. However, as the Inuit example shows, from an external, non familiar, point of view, the dwelled-in environment can be just as well a "natural" environment, even a "wilderness".

Although the damage to the dwelled-in environment is deeply personal, it can be shared with others. In the case of the Inuit, it is collectively acknowledged, and there is a specific procedure (the talking circle) to deal with it. However, as already discussed, the damage to the dwelled-in environment hardly fits the kind of formal requirements necessary for damage to be recognised in our legal and judiciary system, other than claiming that some sort of “cultural distinctiveness" should be preserved.

But we miss the point if we jump to a catch-all category like "cultural distinctiveness". The damage to a dwelled-in environment is not specific to indigenous cultures. Its recognition stems from an evaluative register that human beings, in general, rely on when engaging with the environment on the basis of familiarity. However, the existence of specific institutionalised forms assuring its consideration and communication (as is the case of the talking circle in the Inuit example) is culture-dependent.

To further clarify this point, I will rely on the work of Claire Bouteloup (2008) on the

\footnotetext{
${ }^{16}$ The anthropologist Tim Ingold (2000) has developed an approach to the perception of the environment in terms of "dwelling", relying on the phenomenological tradition, especially Heidegger. The pragmatic approach I discuss here allows us to reframe "dwelling" as a specific mode of engagement with the environment, based on familiarity. This implies that the "dwelling" experience is not the exclusive way that humans relate to the world but a specific mode of coordination with the surrounding environment, which, even if crucial in providing the person an intimate self-assurance, is articulated with others that require a distinction between a subject and an object.
} 
valuation of ecological damages following the Amoco-Cadiz oil spill. ${ }^{17}$ Bouteloup's analysis shows how the qualification of the impacted environment in terms of Brittany's specific environment gives rise to both a mode of valuation based on a domestic worth (as shown by Fourcade) and a recognition of personal attachments to the affected places in the form of a specific cultural identity shared by the inhabitants. As in the case of the Inuits, cultural identity is a way to have a distinct relationship with the environment publicly recognised. In the French case, however, the way to translate this attachment into a legitimate public claim is not to ask for the recognition of specific rights, but rather for the use of a qualification of the environmental damage according to a domestic worth.

This difference between what we observe in the US case and in the French case is related to the specific construction of public justifiability that we find in France, in which, as highlighted by Fourcade, the reference to the common good is still crucial. Nevertheless, the inhabitants interviewed by Bouteloup also speak of additional dimensions of the damage caused by the oil spill, aspects that they share only in very limited circles of familiar people; they are ashamed or reticent to share such issues with non-familiar people (including the researcher), knowing that they lack public relevance. The loss of familiar habits of use and frequentation of their environments reveals a rich bundle of intimate relationships to beings (animals, plants), places and objects that the affected people value and cherish as a constitutive part of the persons they are.

The damage to the dwelled-in environment, however, gives rise less to public denunciation than to forms of sharing and communicating in which empathy plays a crucial role, as in the Inuit talking circle, even if no institution of the kind exists in the French example.

When studying environmental valuation conflicts concerning public decisions impacting the environment or compensations for environmental damage, we constantly come up against

\footnotetext{
${ }^{17}$ See also the contribution of Bouteloup in Bouni et al., 2009.
} 
attributions of value based on familiarity and the difficulty of integrating them into the public process of valuation to which objectivation is so central. We are constantly confronted with problems of radical or constitutive incommensurability.

In fact, through familiar engagement, people develop attachments to beings and objects they value since the latter participate in maintaining their milieu, in which their person is distributed. They are valuable in a way that excludes commensuration, as commensuration would imply considering these persons, objects and other entities of the environment as separate and "equivalent" to others, according to a general qualification or a simple function.

We can, of course, always commensurate them, but this would be meaningless from a dwelling perspective: to commensurate them would mean shifting to a different practical engagement with them. These radically incommensurable beings can be equally valuable to other people but not because we share a standard for judgement - which anyone, a generalised third party, could apply - but because we share the same kind of engagement with these very same beings. "Clues" to understanding the value "from within" are at stake here, not ciphers to decode what makes their worth "from without" (Ingold, 2000).

Of course, we can commensurate the familiar entities to which we are attached, even trade them off, put a price on them or accept compensation as social recognition of our loss. But more often than not this would be a "tragic choice" (Nussbaum 2001), something we are forced to do, or at best a difficult choice that involves suffering. This difficulty and suffering are the sign that we are sacrificing something we value in a way that has no real equivalent.

\section{Final remarks}

Problems of incommensurability become a more precise object for sociological investigation when revisited in terms of critical tensions between modes of valuation based on diverse regimes of action and coordination with the environment. 
In particular, this approach clarifies the terms in which it might be appropriate to speak about problems of "constitutive incommensurability" in environmental valuation. In fact, the experience of $d$ welling is based on a relation of proximity with the environment that resists commensuration because, through dwelling, things and persons are constituted as unique spatio-temporal particulars. This relationship is crucial (or "constitutive") to the "consistency" of the person. ${ }^{18}$

It is thus possible to investigate this radical incommensurability without jumping directly to catchall collective categories, such as cultural identity or sacredness, and to investigate the variety of ways in which people share and communicate with others this mode of valuing based on familiarity. A pragmatic approach - in this, differing from a phenomenological perspective - invites attentiveness to the variety of supports people rely on in order to communicate valuations based on a familiar engagement, according to the variable extension of the sought-after coordination: from situations in which this communication is confined to intimate relationships, to those cases in which communication aims to sustain a community of practices, to situations in which communication is meant to reach an extended political community. The important aspect to retain here is that modes of valuation that are radically incommensurable, since based on familiarity and personal attachments, can be shared with others and can support the constitution of forms of commonality (mise en commun), which do not, however, comply with the grammars of public legitimacy.

Culture thus matters, since it provides resources (words, categories, cultural artefacts...) that can aid in the communication of modes of valuation based on familiarity. However, the need to share these radically incommensurable modes of valuation can also prompt innovation, as is the case of the new repertoires or styles of political activism that we can recognize in

\footnotetext{
${ }^{18}$ From the original meaning of "standing firm", in pragmatic sociology the term "consistency" points to the efforts a person makes to maintain an existential coherence through the multiple modes of action and engagement that are required for living in our societies.
} 
today's various expressions of environmental mobilisation. Activists in environmental struggles are often key actors in this innovation process aimed at finding original ways to bridge the gap between valuations of the environment as a place of familiar attachments, as a resource and as a "common good", where the "commonality" is potentially extended to all of humanity.

The French and US examples I have discussed throughout the paper show the interest of a comparative approach in terms of national cultures of environmental damage valuation, one that should not be limited to understanding the unequal importance attributed in different national contexts to certain legitimate orders of worth in the public space. The comparative approach allows us to identify the relevance, in our societies, of competing definitions of what accounts for public legitimacy: it can be justifiability according to a common good, requiring from people a public engagement; or the aggregation of individual preferences, requiring a normal action. In both cases, problems of incommensurability are crucial, but while, in the justification frame they are openly assumed in public discussion (as problems of order incommensurability) and only partially resolved (through compromise), in the public space as the space of aggregation of preferences, they are confined at best to individuals' "interior forum". At the same time, the comparative approach can reveal the existence of ways to create a commonality of valuation between people, starting from a familiar engagement: to what extent these modes of creating commonality can be taken into account when public decision-making and regulation are at stake is a question open to further analysis. More comparative research is needed in order to clarify the role that political cultures play in ensuring dialogue between diverse constructions of the public and diverse grammars of commonality based on familiarity.

In this respect, studying how forms of valuation of the environment based on familiarity can contribute to a more accurate understanding of sustainability emerges as a particularly 
relevant research field for future investigations. In fact, modes of valuation based on familiarity produce forms of knowledge and practices of intervention in the environment that can contribute to a more sustainable management, in ecological and social terms, of natural resources. One example is the case discussed by Charis Thompson (2002) of elephant conservation in the Kenyan Amboseli Park. The author shows how scientific knowledge can be an ally in revealing the role, in maintaining biodiversity, played by practices that are deeply embedded in traditional ways of living of local populations - in this case, the pastoral activities of the Maasai populations. This result is possible if scientists, such as David Western in the example analysed by Thompson, become sort of "familiar" to the places where they intervene, so as to be able to establish a fruitful dialogue with the local inhabitants. Place-attached experts can play a crucial role as mediators in having familiar languages and practices of valuation included in the definition of standards of management. Nevertheless, this same case study shows how taking into account local practices, and their integration in forms of ecological co-management, can engender long-standing tensions and conflicts, across local-global lines. In fact, the lack of solid "tests of reality" for judging the ecological worth - since the articulation between the local and the global is often uncertain or ignored accounts for the potential fragility of these local arrangements.

In any case, new forms of ecological collaborative management (or co-management) are being devised, in the North and in the South, through ongoing experiments developed in response to environmental challenges (climate change, loss of biodiversity, water-related issues,...). The study of these socio-technical experiments from the perspective of plural modes of engagement with the environment could offer the opportunity to further analyze how conditions are created - or not - for plural languages of valuation to coexist in socially and ecologically sound arrangements (Cheyns, 2011). Far from being exclusively a source of conflict and an obstacle to public decision-making, radical incommensurability can, one 
hopes, be an opportunity for collective explorations of new modes of organizing our life in common, more respectful of our plural ways of engaging with our environments.

\section{Acknowledgment}

I wish to thank Ota de Leonardis, Mihaela Mihai and Gildas Renou for their comments on previous versions of this paper as well as the two anonymous referees for their attentive reading and useful remarks.

\section{Funding}

Work on this paper was supported by the Portuguese Fundação para a Ciência e Tecnologia [FCOMP-01-0124-FEDER-009234] and by the French CNRS [PEPS ESERE 2013].

\section{References}

Adler, M. 1998. 'Law and Incommensurability: Introduction'. University of Pennsylvania Law Review 146: $1169-1184$.

Bénatouil, T. 1999. 'A Tale of Two Sociologies: The Critical and the Pragmatic Stance in Contemporary French Sociology'. European Journal of Social Theory 2(3): 379-396.

Blok, A. 2013. 'Pragmatic sociology as political ecology: On the many worths of nature(s)'. European Journal of Social Theory 16(4): 492-510.

Blokker, P. 2011. 'Pragmatic sociology: Theoretical evolvement and empirical application'. European Journal of Social Theory 14 (3): 251-261.

Boltanski, L. 1990. L'amour et la justice comme compétences. Trois essais de sociologie de l'action. Paris: Métailié.

Boltanski, L. and E. Chiapello. 2005. The New Spirit of Capitalism, London-New York: Verso [First French ed.: Le nouvel esprit du capitalisme Paris, Gallimard 1999].

Boltanski, L. and L. Thévenot. 1999. 'The Sociology of Critical Capacity'. European Journal of Social Theory 2 (3): 359-377.

Boltanski, L. and L. Thévenot. 2006. On Justification: Economies of Worth. Princeton: Princeton University Press [First French ed: De la Justification. Les Economies de la grandeur Paris, Gallimard 1991]. 
Bouni, C., A. Dufour, J.-B. Narcy, and C. Bouteloup. 2009. Préjudices écologiques des marées noires ; revendications et valeurs économiques. Neuilly : Lafon.

Bouteloup, C. 2008. Amoco Cadiz, 1978-2008, Mémoires Vives. Paris : CEDRE.

Breviglieri, M. 2012. 'L'espace habité que réclame l'assurance intime de pouvoir: Un essai d'approfondissement sociologique de l'anthropologie capacitaire de Paul Ricoeur'. Études Ricoeuriennes / Ricoeur Studies 3 (1): 34-52.

Callon, M. (ed.) 1998. The Laws of the Markets. Oxford: Blackwell.

Callon, M., P. Lascoumes and Y. Barthe. 2009. Acting in an Uncertain World. An Essay on Technical Democracy. Cambridge, (MA): MIT Press [First French ed.: Agir dans un monde incertain. Essai sur la démocratie technique Paris, Seuil 2001].

Centemeri, L. 2012. 'The Contribution of the Sociology of Quantification to a Discussion of Objectivity in Economics'. In J.M. Castro Caldas and V. Neves (eds), Facts and Values in Economics. London: Routledge.

Chang, R. (ed.) 1997. Incommensurability, Incomparability, and Practical Reason. Cambridge: Harvard University Press.

Cheyns, E. 2011. 'Multi-stakeholder initiatives for sustainable agriculture : limits of the 'Inclusiveness' paradigm'. In : S. Ponte, P. Gibbon and J. Vestergaard (eds.). Governing through standards: origins, drivers and limitations, pp. 210-235. London : Palgrave Macmillan.

D'Agostino, F. 2003. Incommensurability and Commensuration. The Common Denominator. Aldershot: Ashgate.

Dannenmaier, E. 2008. 'Beyond Indigenous Property Rights: Exploring the Emergence of a Distinctive Connection Doctrine'. Washington University Law Review 86: 53-110.

Descola, P. 2005. Par-delà nature et culture. Paris: Gallimard.

Desrosières, A. 1990. 'How to Make Things Which Hold Together: Social Science, Statistics and the State'. In P. Wagner, B. Wittrock and R. Whitley (eds.) Discourses on Society: The Shaping of the Social Science Disciplines. Dordrecht: Kluger.

Desrosières, A. 1992. 'Discuter l'indiscutable. Raison statistique et espace public'. In A. Cottereau and P. Ladrière (eds.) Pouvoir et légitimité : figures de l'espace public. Paris: Éditions de l'EHESS.

Desrosières, A. 1998. The Politics of Large Numbers: A History of Statistical Reasoning. Cambridge, Mass.: Harvard University Press [First French ed. : La politiques des grands nombres Paris, La Découverte 1993].

Dodier, N. 1993. 'Action as a combination of 'common' worlds'. Sociological Review 41(3) :556-71. 
Doidy, E. 2003. 'La voix des usagers dans les concertations environnementales'. Sociologies pratiques 7: 49-64.

Dosse, F. 1999. The empire of meaning. The humanization of the social sciences. Minnesota: University of Minnesota Press.

Dupuy, J-P, F. Eymard-Duvernay, O. Favereau, A. Orléan, R. Salais and L. Thévenot. 1989. 'L'économie des conventions'. Revue économique 40 (2): 141:406.

Espeland, W. N. 1994. 'Legally Mediated Identity: The National Environmental Policy Act and the Bureaucratic Construction of Interests'. Law and Society Review 28(5): 1149-1180.

Espeland, W. N. and M. L. Stevens. 1998. 'Commensuration as a social process'. Annual Review of Sociology 24: 313-343.

Favereau, O. and E. Lazega (eds.) 2003. Conventions and Structures in Economic Organization: Markets, Networks and Organizations. Cheltenham (UK) - Northampton (MA, USA): Edward Elgar Publishing.

Foster, J. (ed.) 1997. Valuing Nature? Economics, Ethics and Environment. New York: Routledge.

Fourcade, M. 2011. 'Cents and Sensibility: Economic Valuation and the Nature of "Nature"'. American Journal of Sociology 116 (6) : 1721-77.

Funtowicz, S. and J. Ravetz. 1994. 'The worth of a songbird: ecological economics as a post-normal science'. Ecological Economics 10: 197-207.

Godard, O. 2003. 'Développement durable et principes de légitimité'. Information sur les Sciences Sociales 42(3): 375-402.

Gowdy, J. and J.D. Erickson. 2005. 'The approach of ecological economics'. Cambridge Journal of Economics 29: 207-222.

Guggenheim, M. and J. Potthast. 2012. 'Symmetrical twins: On the relationship between ActorNetwork theory and the sociology of critical capacities'. European Journal of Social Theory 15(2): 157-178.

Ingold, T. 2000. The perception of the environment: Essays on livelihood, dwelling and skill. London: Routledge.

Lafaye, C. and L. Thévenot. 1993. 'Une justification écologique ? Conflits dans l'aménagement de la nature'. Revue Française de Sociologie 34(4): 495-524.

Lafaye, C., M. Moody and L. Thévenot. 2000. Forms of Valuing Nature: Arguments and Modes of Justification in Environmental Disputes. In M. Lamont and L. Thévenot (eds.), Rethinking comparative cultural sociology. Cambridge: Cambridge University Press. 
Lamont, M. 2012. 'Toward a Comparative Sociology of Valuation and Evaluation'. Annual Review of Sociology 38: 201-221.

Lamont, M. and L. Thévenot (eds.) 2000. Rethinking comparative cultural sociology: Repertoires of Evaluation in France and the United States. Cambridge: Cambridge University Press.

Latour, B. 1993. We have never been modern. Cambridge, MA: Harvard University Press.

Latour, B. 1998. 'To modernise or ecologise? That is the question'. In B. Braun (ed.), Remaking Reality: Nature at the Millennium. Florence, KY: Routledge.

Martinez-Alier, J. 2002. The Environmentalism of the Poor. A study of ecological conflicts and valuation. Cheltenham, UK: Elgar.

Martinez-Alier, J. 2008. 'Languages of Valuation'. Economic and Political Weekly 43(8): 28-32.

Martinez-Alier, J., J. O’Neill and G. Munda. 1998. 'Weak Comparability of Values as a Foundation for Ecological Economics'. Ecological Economics 26: 277-286.

Milanesi, J. 2011. 'Une histoire de la méthode d'évaluation contingente'. Genèses 84 (3): 6-24.

Moody, M. and L. Thévenot. 2000. 'Comparing Models of Strategy, Interests, and the Common Good in French and American Environmental Disputes'. In M. Lamont and L. Thévenot (eds.), Rethinking comparative cultural sociology. Cambridge: Cambridge University Press.

Munda, G. 2008. Social Multi-Criteria Evaluation for a Sustainable Economy. Berlin: Springer.

Nussbaum, M. 2001. The Fragility of Goodness: Luck and Ethics in Greek Tragedy and Philosophy. Cambridge: Cambridge University Press.

O’Neill, J. 1997. 'Managing Without Prices: The Monetary Valuation of Biodiversity'. Ambio 26

(8): 546-50.

O’Neill, J. 2007. Markets, Deliberation and Environment. London: Routledge

O’Neill, J., A. Holland and A. Light. 2008. Environmental Values. London and New York: Routledge.

Pellizzoni, L. 2003. 'Knowledge, Uncertainty and the Transformation of the Public Sphere'. European Journal of Social Theory 6(3): 327-355.

Picou, J. S. 2000. 'The 'Talking Circle' as Sociological Practice: Cultural Transformation of Chronic Disaster Impacts'. Sociological Practice 2(2): 77-97.

Porter, T. M. 1995. Trust in Numbers. The Pursuit of Objectivity in Science and Public Life. Princeton: Princeton University Press.

Raz, J. 1986. The Morality of Freedom. Chicago: Clarendon Press. 
Richard-Ferroudji, A. 2011. 'Limites du modèle délibératif : composer avec différents formats de participation'. Politix 96(4): 161-181.

Schön, D. and M. Rein. 1994. Frame Reflection: Toward the Resolution of Intractable Policy Controversies. New York: Basic Books.

Silber, I. F. 2003. 'Pragmatic sociology as cultural sociology: beyond repertoire theory?'. European Journal of Social Theory 6(4): 427-49.

Spash, C. L. 1999. 'The development of environmental thinking in economics'. Environmental Values 8(4): 413-435.

Stark, D. 2009. The Sense of Dissonance: Accounts of Worth in Economic Life. Princeton and Oxford: Princeton University Press.

Sunstein, C.R. 1994. 'Incommensurability and Valuation in Law'. Michigan Law Review 92 :779-861.

Thévenot, L. 1990. 'L'action qui convient'. In P. Pharo and L. Quéré (eds.) Les formes de l'action. Paris: Ed. de l'EHESS.

Thévenot, L. 2001. 'Pragmatic regimes governing the engagement with the world'. In K. Knorr-Cetina, T. Schatzki and E. von Savigny (eds.) The Practice Turn in Contemporary Theory. London: Routledge.

Thévenot, L. 2006. L'action au pluriel. Sociologie des régimes d'engagement. Paris: La Découverte. Thévenot, L. 2007. 'The Plurality of Cognitive Formats and Engagements: Moving between the Familiar and the Public'. European Journal of Social Theory 10(3): 413-27.

Thévenot, L., F. Eymard-Duvernay, O. Favereau, A. Orléan and R. Salais. 2005. 'Values, coordination and rationality: the economy of conventions'. In A. N. Oleinik (ed.) The Institutional Economics of Russia's Transformation. Aldershot: Ashgate.

Thompson, C. 2002. 'When Elephants Stand for Competing Models of Nature'. In A. Mol and J. Law eds., Complexities: Social Studies of Knowledge Practices. Durham: Duke University Press.

Trainor, S.F. 2006. 'Realms of Value: Conflicting Natural Resource Values and Incommensurability'. Environmental Values 15: 3-29.

Wagner, P. 1999. 'After Justification: Repertoires of evaluation and the sociology of modernity'. European Journal of Social Theory 2(3): 341-57.

Zelizer, V. A. 1997. The Social Meaning of Money. Princeton, N.J.: Princeton University Press. 